\title{
Polyflagellated macrocephalic spermatozoa: failure factor in IVF/ICSI
}

\author{
Fanny Mohamed ${ }^{1}$, Dia Jean-Marc ${ }^{2 *}$, Adjoussou Stephane ${ }^{1}$, Coulibaly Founzegue ${ }^{3}$, \\ Fomba Minata ${ }^{1}$, Aka Edele ${ }^{1}$, Koffi Abdoul ${ }^{1}$, Kone Mamourou ${ }^{1}$
}

\begin{abstract}
${ }^{1}$ Department of Gynecology, University and Hospital Center of Yopougon (CHUY), Abidjan, Côte d'Ivoire ${ }^{2}$ Department of Gynecology, University and Hospital Center of Treichville (CHUT), Abidjan, Côte d'Ivoire ${ }^{3}$ Institut Pasteur - Felix Houphouet Boigny University, Abidjan, Côte d'Ivoire
\end{abstract}

Received: 21 August 2017

Accepted: 16 September 2017

\section{*Correspondence:}

Dr. Dia Jean-Marc,

E-mail: jmlaminedia@yahoo.fr

Copyright: (C) the author(s), publisher and licensee Medip Academy. This is an open-access article distributed under the terms of the Creative Commons Attribution Non-Commercial License, which permits unrestricted non-commercial use, distribution, and reproduction in any medium, provided the original work is properly cited.

\begin{abstract}
The authors report two cases of male infertility characterized by spermatic abnormalities of polyflagellated macrocephalic spermatozoa type affecting the entire gametes population. They demonstrate, on the one hand, the technical limitations of microinjection with such spermatozoa due to the large volume of their head and, on the other hand, the unfavourable outcome of the IVF-ICSI with this type of spermatozoa carrying abnormalities constituent. Molecular analysis of the somatic DNA of these subjects revealed a homozygous c.144delC mutation of the Aurora Kinase C gene. Consanguinity at the level of these subjects' parents appears to be the main risk factor. This situation constitutes a factor of failure of the IVF and leads to direct the couple towards the donation of gametes or the adoption as solution to the parental project.
\end{abstract}

Keywords: Macrocephaly, Microinjection, Spermatozoa

\section{INTRODUCTION}

The introduction and development of oocyte microinjection of spermatozoa in Assisted Reproductive Technology (ART) helped to resolve the infertility of male origin. However, there are limits to this technique which in many cases is a palliative solution to the major qualitative and quantitative disturbances of spermatogenesis. Indeed, some exceptional pathological situations represented mainly by structural anomalies affecting the whole gametes population make ICSI ineffective. This is the case of polyflagelated macrocephalic spermatozoa, which are characterized by a large head size and several flagella. We report two cases that will allow us to explain the contribution of cytogenetics in understanding the anomaly and to demonstrate the limitations of IVF-ICSI.

\section{CASE REPORT}

\section{Case 1}

Mr. MD, 38, a professional bricklayer, has consulted with his wife for primary infertility for 11 years. His personal medical history was unusual and he did not smoke tobacco nor drink alcohol. The spermogram, after four tests, showed out of a volume of $7 \mathrm{ml}$, a count of 0.1 Million / $\mathrm{ml}$ with a mobility of $3 \%$ spermatozoa "b". Out of a count of 66 spermatozoa, the spermocytogram found $95 \%$ of atypical forms dominated all by macrocephalus type head abnormalities and multiple type flagellum flagellar abnormalities. Such a spermatic balance therefore concluded with extreme oligoasthenospermia with multiple flagella macrocephalic spermatozoa. In addition, the spouse of Mr. MD, aged 33, 
presented an ovarian reserve in the process of collapse. After ovarian stimulation for IVF-ICSI, the ovarian response was limited to 3 oocytes. At the time of the microinjection attempt, the teratospermia proved that only 3 injectable spermatozoa but of atypical morphology could be extracted from the ejaculate. An embryo was obtained and transferred. However, there was a failure of IVF-ICSI. Following the failure of IVF-ICSI, a control of the pre-microinjection test made it possible to extract live, but non-injectable spermatozoa due to the atypia affecting the spermatic heads (large size of the head).

In view of these major anomalies and considering the major genetic abnormality of these spermatozoa with little evolutionary potential of the embryos obtained, an analysis of the chromosomal content of spermatozoa by fluorescence in situ hybridization (FISH) technique was performed. The probes used were: Xp11.1-q11 DXZ1 spectrum green, Yq12 DYZ1 spectrum orange, 18p11.1q11.1 D18Z1 spectrum aqua, brand Vysis (Abbott). After washing and fixation of the spermatozoa, in hybridization technique on a slide and after several attempts, it was not possible to obtain interpretable signals in the spermatozoa. This resulted in a profound anomaly of the structure of sperm nuclei. A molecular study carried out at these nuclei revealed a homozygous c.144delC mutation of the Aurora Kinase $\mathrm{C}$ gene.

\section{Case 2}

Mr. ZA, 34, a shopkeeper, has consulted for primary infertility for 5 years. The interrogation did not find any particular personal history. His spermogram showed out of a volume of $5 \mathrm{ml}$, a count of 10 million spermatozoa per $\mathrm{ml}$. The mobility was altered with $10 \%$ of slow moving spermatozoa. In spermocytograms, $100 \%$ of atypical forms were observed with predominant atypia in the spermatic head and flagellum in the form of multiple flagellated macrocephalic spermatozoa. The pre-microinjection gradient test did not find any typical form usable in IVF-ICSI technique. A cytogenetic analysis of sperm by in situ fluorescence hybridization using X, Y, 1, and 18 chromosome specific probes showed a polyploid content for all the cells analyzed. The molecular study of the somatic DNA of $\mathrm{Mr} \mathrm{ZA}$ showed a homozygous mutation c.144delC of the gene Aurora Kinase C.

In our two patients, the plasma karyotype was normal and the search for micro deletion of the Y chromosome was negative. The family survey did not find any similar cases. However, Mr. MD and Mr ZA, both from the same geographical area and the same ethnic group were born from consanguineous parents.

\section{DISCUSSION}

A dozen years ago, Barrière reported the words of an editorial in Le Monde speaking about ICSI as a miracle treatment for male infertility. ${ }^{1}$ For a while, it was thought that ICSI could solve everything, because of the fact that it required only one live spermatozoa per oocyte, whether this spermatozoid is ejaculated or surgically removed, cryopreserved or not. Today, it is known that ICSI also fails in some cases. New ways of research have been attempted: the ICSI with spermatids, and soon we may be working with sperm obtained after repopulating the seminiferous tubules by stem cells. There are currently many spermiological limits to the ART management.

\section{Role of spermatozoid}

The spermatozoa does not simply play an activating role of the oocyte for fertilization. It brings the necessary heritage for the early embryonic development, and to ensure the development of the conceptus to the term.

\section{Genetic quality of spermatozoid}

Abnormalities in the number of chromosomes or aneuploids are the most frequently observed abnormalities involved in repetitive miscarriages and alterations in gametogenesis. ${ }^{1}$ Since the development of FISH techniques, the study of chromosomes in spermatozoa has become relatively easy. The analysis by in situ hybridization allows an accurate estimation of the proportion of spermatozoa carrying a disomy (presence of two chromosomes of the same pair in a haploid cell) or of a diploidy (existence of a complete set of pairs Chromosomes in the human species, or 22 pairs of autosomes and 1 pair of sex chromosomes). ${ }^{2}$ A review of the literature on studies of sperm analysis by FISH in fertile and infertile males shows that rates of chromosomal abnormalities are variable. For some authors such as Guttenbach and Miharu, there is no difference in the proportion of aneuploidy between fertile and infertile men; for the others, on the contrary, higher rates of aneuploidy are observed in infertile males with normal somatic karyotyping. ${ }^{3-9}$

Some authors report a correlation between sperm quality and proportion of aneuploidy. ${ }^{7,8,10-12}$ Indeed, according to them, there is a relationship between aneuploidy and the concentration of spermatozoa and, on the other hand, between aneuploidy and the mobility of spermatozoa. ${ }^{8,12}$ Thus, in the case of pathological spermatogenesis with normal karyotype, there is a strong link between oligospermia and aneuploidies. It does not seem to be a link between teratospermia and aneuploidy, except for some specific morphological anomalies (macro, microcephalic). ${ }^{1}$ Indeed, concerning the correlation teratospermia and chromosomal abnormalities, opinions are divided. For some authors like Viville and Vicari, a severe teratospermia is accompanied by no greater incidence of aneuploidy. ${ }^{13,14}$ Other authors, on the other hand, report a significantly higher rate of chromosomal abnormalities of spermatozoa in case of teratospermia. ${ }^{15}$ In case 2, the analysis by FISH technique for chromosomes $\mathrm{X}, \mathrm{Y}$ and 18 revealed spermatic chromosomal abnormalities. These findings are consistent with those of Mateu, who also reports a high 
incidence of aneuploidy-like abnormalities in the $\mathrm{X}, \mathrm{Y}$ and 18 chromosomes. ${ }^{16}$ Indeed, in a study published in 2006, Mateu found a $91.2 \%$ rate of aneuploidy in subjects with polyflagellated macrocephalic spermatozoa. Given the presence of morphological anomalies of the polyflagellated macrocephalic type, one wonders about the factors favoring the occurrence of such atypies. Is it an acquired abnormality (in relation to toxic exposure) or is it a genetic abnormality?

\section{Risk factors}

In the literature, few studies point to a link between possible factors such as toxic and this type of spermatic abnormality. In a study by Rosemberg in 1985, he reported toxic effects of chemical exposure of workers in an oil refinery on sperm morphology. ${ }^{17}$ It showed a link between the morphological abnormality and the chemical exposure. In a relatively recent publication, Mateu reported a case of polyflagellated macrocephalic spermatozoa with polyploidy (a batch of chromosomes of more than 23 pairs) in a 38 -year-old patient who worked in an oil refinery with daily exposure to chemical agents such as sulfuric acid, asphalt and ammonium. ${ }^{16}$

Other risk factors such as ethnic origin and consanguinity may be related to the presence of polyflagellated macrocephalic spermatozoa. Indeed, like us, Dieterich also found this type of abnormality in subjects from the same ethnic group as our two patients and he also found the notion of consanguinity. ${ }^{18}$ But the link between these factors and the anomaly is worth being demonstrated in other studies conducted on a larger series.

\section{Pathogenesis}

In general, we know that the prime mover of the abnormality is a disturbance of meiosis I and II. ${ }^{19,20}$ It is in fact a meiotic non-disjunction with no cell division and spermiogenesis. In a study on ten patients with polyploid macrocephalic spermatozoa, Dieterich demonstrated a mutation of the Aurora Kinase C gene (AURKC) in a molecular analysis. ${ }^{18}$ For him, only the c144delC homozygous mutation is related to infertility. Heterozygous patients do not have a decreased fertility. In our work, our two patients are homozygous for the c144delC mutation of the Aurora Kinase C gene.

\section{Clinical consequences}

The results of the ICSI using spermatozoa with abnormalities in cytogenetic analysis have been evaluated by several authors. ${ }^{10,12,21,22}$ For these authors, it appears that sperm chromosomal abnormalities have a deleterious effect on the ICSI results, thus reducing pregnancy rates. In a case-control study on the fertility and the embryo fate in a series of 17 patients with various morphological spermatic abnormalities including macrocephaly, Kahraman observed a statistically significant decrease in pregnancy rate compared to the control group $(9.1 \%$
Versus $40 \%) .{ }^{22} \mathrm{He}$ found a limited number of transferable embryos and out of 22 cycles only two pregnancies were obtained but without favorable outcome. He concluded that the presence of macrocephalic spermatozoa greatly alters fertility and compromises the chances of pregnancy. This conclusion is also shared by other authors who also observe a greater risk of genetic abnormalities of the embryos obtained with an increased incidence of aneuploidy and mosaics. ${ }^{23,24}$

Like most authors, we believe that the presence of polyflagellated macrocephalic spermatozoa polyploid does not suggest the conception of viable embryo. ${ }^{18,20}$ This contraindicates the IVF-ICSI and the alternatives we propose are the adoption and the gamete donation.

\section{CONCLUSION}

The IVF-ICSI presented as a miracle solution to male infertility does not always bring the solution. Severe oligoasthenospermia with significant teratospermia may be the sign of a deep disorder of sperm structure. The cytogenetic study by in situ hybridization can help to clarify the nature of chromosomal abnormalities while molecular study can identify the gene mutation responsible in some cases. An oligoasthenospermia with monomorphic total teratospermia constituted by polyflagellated macrocephalic spermatozoa is one example. Apart from the technical difficulty of ICSI related to the large size of the spermatozoa head, such a disturbance of the spermogram contraindicates the use of sperm in medically assisted procreation because the embryos have no evolutionary potential. After being informed of the risk, couples should be discouraged from intra-conjugal ART.

\section{Funding: No funding sources Conflict of interest: None declared \\ Ethical approval: Not required}

\section{REFERENCES}

1. Barrier P. The spermiological limits to AMP.J Gynecol Obstet Biol Reprod. 2005;34:5S34-5S37.

2. In't Veld PA, Broekmans FJ, France HF, Pearson PL, Pieter MH, Van Kooij RJ. Intracytoplasmic sperm injection (ICSI) and chromosomal abnormal spermatozoa. Hum Reprod. 1997;12:752-4.

3. Guttenbach M, Martinez-Exposito MJ, Michelmann HW, Engel W, Schmid M. Incidence of diploid and disomic sperm nuclei in 45 infertile men. Hum Reprod. 1997;12:468-473.

4. Miharu N, Best RG, Young SR. Numerical chromosome abnormalities in spermatozoa of fertile and infertile men detected by fluorescence in situ hybridization. Hum Genet. 1994;93:502-6.

5. Bernardini L, Borini A, Preti S, Conte N, Flamigini C, Capitanio GL, Venturini PL. Study of analgesia in normal and abnormal germ cells from fertile and infertile men. Hum Reprod. 1998;13:3406-13. 
6. Aran B, Blanco J, Vidal F, Vendrell JM, Egozcue S, Barri PN et al. Screening for abnormalities of chromosomes $\mathrm{X}, \mathrm{Y}$, and 18 and for diploidy in spermatozoa from infertile men participating in an in vitro Fertilization-intracytoplasmic sperm injection program. Fertil Steril. 1999;72:696-701.

7. Ushijima C, Kumasako Y, Kihaile PE, Hirotsuru K, Utsunomiya T. Analysis of chromosomal abnormalities in human spermatozoa using multicolor fluorescence in situ hybridization. Hum Reprod. 2000;15:1107-11.

8. Vegetti W, Van Assche E, Frias A, Verheyen G, Bianchi MM, Bonduelle $\mathrm{M}$ et al. Correlation between semen parameters and sperm aneuploidy rats investigated by fluorescence in-situ hybridization in infertile men. Hum Reprod. 2000;15:351-365.

9. Martin RH, Rademaker AW, Greene C, Ko E, Hoang T, Barclay L, Chernos J. A comparison of the sperm chromosome abnormalities in men with mild, moderate, and severe oligozoospermia. Biol Reprod. 2003;69:535-9.

10. Bernadini L, Gianaroli L, Fortini D, Conte N, Magli $\mathrm{C}$, Cavani S et al. Frequency of hyper, hypohaploidy and diploidy in ejaculate, epididymal and testicular germ cells of infertile patients. Hum Reprod. 2000;15:2165-72.

11. Nishikawa N, Murakami I, Ikuta K, Suzumori K. Sex chromosomal analysis of spermatozoa from infertile men using fluorescence in situ hybridization. J Assist Reprod Genet. 2000;17:97-102.

12. Rubio C, Gil-Salom M, Simon C, Vidal F, Rodrigo $\mathrm{L}$, Minguez $\mathrm{Y}$ et al. The authors of this study were able to evaluate the incidence of sperm chromosomal abnormalities in a group of patients. Hum Reprod. 2001;16:2084-92.

13. Viville S, Mollard R, Bach ML, Falquet C, Gerlinger $\mathrm{P}$, Warter S. Do morphological anomalies reflect chromosomal aneuploidies? Case report. Hum Reprod. 2000;15:2563-6.

14. Vicari E, Perdichizzi A, De Palma A, Burrello N, D'Agata R, Calogero AE. Globozoospermia is associated with chromatin structure abnormalities: case report. Hum Reprod. 2002;17:2128-33.

15. Lewis-Jones I, Aziz N, Seshadri S, Douglas A, Howard P. Sperm chromosomal abnormalities are linked to sperm morphologic deformities. Fertil Steril. 2003;79:212-5.
16. Mateu E, Rodrigo L, Prados N, Gil-Salom M, Remohi J, Pellecier A et al. High incidence of chromosomal abnormalities in large-headed and multiple-tailed spermatozoa. J Androl. 2006;27:6-10.

17. Rosemberg MJ, Wyrobek AJ, Ratcliffe J, Gordon LA, Watchmaker G, Fox SH et al. Sperm as an indicator of reproductive risk among petroleum refinery workers. Br J Ind Med. 1985;42:123-7.

18. Dieterich K, Rifo RS, Faure AK, Hennebicq S, Amar $\mathrm{BB}$, Mohamed $\mathrm{Z}$ et al. Homozygous mutation of AURKC yields large-headed polyploid spermatozoa and causes male infertility. Nat Genet. 2007;39:6615 .

19. Achard V, Guichaoua MR. Macrocephalic spermatozoa polyflagelle syndrome and Medical Assistance to the Procreation. Androl. 2005;15:1858 .

20. Devillard F, Metzler-Guillemain C, Pelletier R, De Robertis C, Bergues U, Hennebicq $S$ et al. Polyploidy in large-head sperm: FISH study of three cases. Hum Reprod. 2002;17:1292-8.

21. Pfeffer J, Pang MG, Hoegerman SF, Osgood CJ, Stacey MW, Mayer J et al. Aneuploidy infertility in semen fractions from ten oligoasthenoteratozoospermic patients donating sperm for intracytoplasmic sperm injection. Fertil Steril. 1999;72:472-8.

22. Karhaman S, Akarsu C, Cengiz G, Dirican K, Sözen E, Belgin C et al. Fertility of ejaculated and testicular megalohead spermatozoa with intracytoplasmic sperm injection. Hum Reprod. 1999;14(3):726-730.

23. Gianaroli L, Magli MC, Ferraretti AP, Iammarrone E. Preimplantation diagnosis after assisted reproduction techniques for genetically-determined male infertility. J Endocrinol Invest. 2000;23:711-6.

24. Silber S, Escudero T, Lenahan K, Abdelhadi I, Kilani $\mathrm{Z}$, Munne S. Chromosomal abnormalities in embryos derived from testicular sperm extraction. Fertil Steril. 2003;79:30-8.

Cite this article as: Mohamed F, Jean-Marc D, Stephane A, Founzegue C, Minata F, Edele A et al. Polyflagellated macrocephalic spermatozoa: failure factor in IVF/ICSI. Int J Reprod Contracept Obstet Gynecol 2017;6:5141-4. 